\title{
Direitos humanos e vulnerabilidades atravessadas
}

\author{
Pâmela Copetti Ghisleni' (iD) 0000-0003-0166-9462 \\ Doglas Cesar Lucas ${ }^{1,2}$ (i) 0000-0003-3703-3052 \\ 'Faculdade CNEC Santo Ângelo, Santo Ângelo, RS, Brasil. 98801-015 \\ ${ }^{2}$ Universidade Regional do Noroeste do Estado do Rio Grande do Sul, ljuí, RS, Brasil.
}

98700-000

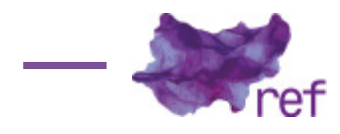

Resumo: Neste texto intentamos analisar o Caso Gonzales Lluy vs. Equador, da Corte Interamericana de Direitos Humanos, cujo decisum condenou o Estado réu pelas violações de direitos humanos de Talía Gabriela Gonzales Lluy em virtude de contágio pelo vírus HIV. O estudo leva em consideração especialmente as temáticas da diferença e da(s) vulnerabilidade(s), as quais saltam aos olhos nesta demanda, delineando todo o julgamento que, afinal, reconheceu a discriminação interseccional a que foi submetida Talía. A partir de revisão crítico-reflexiva dos temas pautados e da utilização da fenomenologia hermenêutica, neste texto pretendemos evidenciar que o caso ora em discussão pode se constituir, guardadas as devidas proporções, em um importante precedente da Corte Interamericana em termos de direitos econômicos, sociais e culturais.

Palavras-chave: Corte interamericana; direito internacional; direitos humanos; discriminação interseccional.

\section{Human Rights and Vulnerabilities Affected}

Abstract: This text attempts to analyze the case Gonzales Lluy vs. Ecuador, of the Inter-American Court of Human Rights, whose decision condemned the defendant State for the human rights violations of Talía Gabriela Gonzales Lluy due to HIV infection. The study takes into account, in particular, the issues of difference and vulnerability(ies), which stand out in this demand, delineating all the judgment that, after all, recognized the intersectional discrimination that was submitted to Talía. Based on a critical-reflective review of the themes and the use of hermeneutic phenomenology, this text intends to show that the case under discussion can be constituted, in due proportion, in an important precedent of the Inter-American Court in terms of economic, social, and culture.

Keywords: Inter-American Court; International right; Human rights; Intersectional discrimination.

\section{A discriminação interseccional no caso Gonzales Lluy y Otros vs. Equador \\ Introdução}

Passada a ilusão moderna da igualdade abstrata, um novo movimento em prol do reconhecimento de demandas identitárias passou a ganhar fôlego a partir de 1960, tendo repercussão, também, na América Latina. A emergência desse importante acontecimento desorganizou dicotomias jurídicas até então solidamente estabelecidas, desafiando os Estados e as sociedades a conceberem o sujeito a partir de um outro olhar, capaz de evidenciar que é demasiadamente simplório reduzir o ser humano a uma só "coisa". Isto é, um homem nunca é somente um homem. Ele carrega consigo traços de identificação que o particularizam, que o aproximam e em um movimento genuinamente ambivalente o distanciam dos demais. Não se pode negar, no entanto, que a complexidade que delineia a sociedade contemporânea afeta 
também o fenômeno da discriminação: surgem outras formas, mais sofisticadas, imbricadas, emboladas de exclusão social.

À luz dessas questões, neste texto pretendemos analisar a categoria da discriminação interseccional a partir do Caso Gonzales Lluy vs. Equador, cuja sentença da Corte Interamericana de Direitos Humanos, órgão judicial autônomo do Sistema Interamericano de Direitos Humanos (SIDH), condenou aquele Estado por violação aos direitos de Talía, que em tenra idade contraiu HIV em uma transfusão sanguínea, circunstância atravessada (e não simplesmente somada) a outras vulnerabilidades, determinantes a exclusão social e discriminação a que foi, junto de sua família, submetida.

Para desenvolvimento da pesquisa, valemo-nos do método da fenomenologia hermenêutica, consistente na revisão crítico-reflexiva dos temas transmitidos pela tradição filosófica por meio da linguagem, abordagem que permite a análise dos fenômenos estudados no plano da historicidade, favorecendo a compreensão de que o "fazer jurídico" é mais do que um ato passivo de subsunção (Lenio STRECK, 2014).

A pesquisa está estruturada em duas partes. Primeiramente, abordamos aspectos históricos e procedimentais do sistema interamericano, notadamente no que diz respeito à Corte. Enfim, na segunda parte, discutimos o Caso Gonzales Lluy vs. Equador, cuja sentença, relativamente recente, é ainda pouco explorada na cena acadêmica nacional, muito embora suas potencialidades guardadas as devidas proporções - em se tornar um precedente fundamental nos sistemas regionais de proteção de direitos humanos no que diz respeito aos direitos econômicos, sociais e culturais.

\section{1 "Nosso norte é o Sul": o sistema interamericano de proteção}

Nosso norte é o Sul. Não deve haver norte, para nós, senão por oposição ao nosso Sul. Por isso agora pomos o mapa ao revés, e então já temos a exata ideia de nossa posição, e não como querem no resto do mundo. Joaquín Torres García (1944)

A frase que prefacia esta seção, do uruguaio Joaquín Torres García, é alusiva à sua belíssima "América Invertida". Em 12 de outubro de 1492, Cristóvão Colombo chegava às Américas. García (1874-1949) propôs, então, um mapa nestes termos: olhando o mundo numa perspectiva outra, e é a partir dessa territorialidade outra que devemos compreender o sistema interamericano e as suas curiosas nuanças.

Uma primeira observação importante reside na constatação de que se está a tratar de uma região marcada por elevado grau de exclusão e desigualdade social, na qual persistem enraizadas a violência e a impunidade. Dois fatores fundamentais, portanto, marcam o contexto latino-americano: o período dos regimes ditatoriais e a (falha) transição para os regimes democráticos, na década de 1980, na Argentina, Chile, Uruguai e Brasil. Nesses períodos autoritários, os mais básicos direitos e liberdades foram violados. Execuções sumárias, desaparecimentos forçados, torturas sistemáticas, prisões ilegais e arbitrárias, perseguições políticas e abolição das liberdades de expressão, reunião e associação fizeram parte do cotidiano das pessoas (Flávia PIOVESAN, 2006).

Esta circunstância de existirem governos tiranos é determinante para a concretização ou violação de direitos humanos, tendo em vista a relação indissociável que se estabelece entre tais direitos e a democracia. A instalação de um governo democrático demanda não somente formalidades burocráticas ou legislativas, mas o incentivo à efetiva consolidação do regime, prerrogativa que ainda não foi plenamente realizada no contexto latino-americano (e ora e outra, bem o sabemos, mais retrocedemos do que avançamos rumo à solidificação do ambiente democrático). Ou seja, entre a instalação de um governo democrático e a consolidação desse governo existe um grande percurso a ser trilhado. É possível compreender, nesse sentido, as razões pelas quais as primeiras atividades da Comissão Interamericana de Direitos Humanos (CIDH) se circunscreveram ao diálogo com autoridades de governo e ao monitoramento da situação dos direitos humanos nos contextos de ruptura do regime democrático-constitucional (Katya SALAZAR; Daniel CERQUEIRA, 2015). Essa dinâmica traduz, em certa medida, o fato de que a universalização dos direitos civis e políticos não se vê completa sem o enfrentamento da violação aos direitos econômicos, sociais e culturais. Essa mesma percepção pode ser encontrada em Guillermo O'Donnell (1998), para quem a extrema pobreza e a desigualdade social fragilizam (quando não tornam inoperante) o efetivo exercício de direitos formais, ainda que em contextos democráticos.

Não se pode esquecer, além disso, que o sujeito latino-americano personifica justamente a ideia do Outro, do bárbaro, tendo em vista que a América colonizada pelos portugueses e espanhóis foi apropriada (e castrada) pelo discurso Moderno do Eu europeu universalizado e abstrato. Nesse sentido, o "rapaz latino-americano sem dinheiro no banco, sem parentes importantes e vindo do interior", a que se refere Belchior na sua inveterada composição de 1976, ilustra sonora e lindamente o sujeito que nasce da opressão, da miséria e da escassez, circunstâncias que vão reverberar em seu processo de subjetivação e, portanto, em categorias como o self e o status. 
A região continua, ainda hoje, problemática no que diz respeito à desigualdade social, enfrentando dificuldades na concretização da democracia e de um padrão adequado de desenvolvimento sustentável. Recente relatório elaborado pela Comissão Econômica para a América Latina e o Caribe (CEPAL), intitulado "Panorama Social da América Latina", demonstrou que, embora entre 2008 e 2015 a desigualdade na distribuição de renda tenha diminuído na América Latina, o ritmo de declínio desacelerou entre 2012 e 2015, de modo que os níveis atuais de desigualdade seguem preocupantemente altos. Verificou-se, também, que o gênero e a condição étnico-racial ainda são fatores-chave na desigualdade estrutural que se instalou (ou foi instalada) na região (CEPAL, 2013).

Entretanto, é importante conjugar nessa análise o fato de que atualmente existe um movimento tendente a afirmar uma posição diferente da sociedade latino-americana em relação ao seu passado de exclusão e exploração, fortalecendo percepções outras que escapem dos reducionismos que analisam negativamente a região (Doglas Cesar LUCAS; Ana Righi CENCI, 2014). Com efeito, "todo la historia de Latinoamérica, al menos desde que el europeo llego a ella, es historia de derechos humanos" (Eugenio Raúl ZAFFARONI, 1989, p. 22), de modo que se cada fração de (in)consciência do nosso ser está colonizada pela opressão a que o povo latinoamericano foi submetido, essa mesma fração consciente tem a lúcida percepção de que temos direitos e de que algo nos aproxima daqueles indivíduos do Norte a que se refere Joaquín Torres García (1944).

O SIDH é formado por quatro diplomas normativos essenciais: a Declaração Americana dos Direitos e Deveres do Homem (DADH), a Carta da Organização dos Estados Americanos, a Convenção Americana de Direitos Humanos (CADH) e o Protocolo Adicional à Convenção Americana sobre Direitos Humanos em Matéria de Direitos Econômicos, Sociais e Culturais (Protocolo de San Salvador). ${ }^{1}$ Tais diplomas sustentam os dois regimes de proteção do SIDH (André RAMOS, 2012): um baseado na Carta da Organização dos Estados Americanos (OEA) e outro na Convenção Americana, também conhecida por Pacto de São José da Costa Rica, o mais importante deles. A fim de dar efetividade ao sistema, a Convenção Americana conta com um aparato que é integrado pela Comissão Interamericana de Direitos Humanos (CIDH), órgão da OEA, e pela Corte Interamericana (Corte IDH), órgão autônomo e responsável pelo monitoramento e implementação daqueles direitos que enuncia, tendo como principal função a observância e proteção dos direitos humanos nas Américas.

A CIDH, criada em 1959 e formalmente instalada em 1960, tem sede em Washington, assumindo competência em face de todos os Estados da Convenção Americana, relativamente aos direitos humanos nela previstos, e perante todos os Estados membros da OEA, quanto aos direitos garantidos na Declaração Americana de 1948. A Comissão conta com sete membros eleitos na Assembleia Geral da OEA para um período de quatro anos, possibilitando-se a reeleição apenas uma vez. Os comissários devem ser pessoas de alta qualidade moral e reconhecida competência na temática dos direitos humanos.

Em resumo, a Comissão é órgão quase judicial, dotado, por um lado, de funções de cunho político-diplomático e, por outro, de atribuições jurisdicionais no tocante ao recebimento dos casos individuais de violações de direitos humanos. Sua função é a promoção da observância e defesa dos direitos humanos no território dos Estados membros da OEA, ainda que não seja parte na Convenção Americana. Por conseguinte, a jurisdição da Comissão não se restringe aos Estados que ratificaram o Pacto de São José da Costa Rica, já que, no caso de não ratificação do Pacto, também poderá haver supervisão e responsabilização internacional pela CIDH por violações aos direitos previstos na Declaração Americana, que lhe é anterior (1948) e, mais do que isso, materializa o marco inicial da construção do SIDH.

A Comissão possui funções promocionais, consultivas e de proteção de direitos humanos. A função promocional reside na assessoria aos Estados para fomentar a consciência a respeito da importância dos direitos humanos. No âmbito consultivo, a CIDH pode elaborar tratados e convenções. Em termos de proteção, a Comissão pode promover a investigação in loco sobre a situação dos direitos humanos. ${ }^{2}$

Dentre as importantes atribuições da Comissão também está a elaboração de relatórios conclusivos informando se o Estado violou ou não a Convenção Americana. Sendo assim, o Estado sancionado pela Comissão por violação de suas obrigações internacionais será submetido a

\footnotetext{
${ }^{1}$ Não se desconhece, contudo, o fato de que existem inúmeros outros documentos de igual relevância, a exemplo do Protocolo Adicional à Convenção Americana sobre Direitos Humanos referente à Abolição da Pena de Morte (ORGANIZAÇÃO DOS ESTADOS AMERICANOS (OEA). Protocolo Adicional à Convenção Americana sobre Direitos Humanos Referente à Abolição da Pena de Morte, 08/06/1990. Disponível em http://www.planalto.gov.br/ccivil_03/ decreto/D2754.htm. Acesso em 25/11/2017).

2 Observe-se que o Brasil, ao depositar a carta de adesão à Convenção Americana, fez a declaração interpretativa de que os arts. 43 e 48, alínea "d", não incluem o direito automático de visitas e inspeções in loco da Comissão Interamericana de Direitos Humanos, as quais dependerão da anuência expressa do Estado. As razões da referida interpretação, em que pese não expressamente declaradas, em muito se devem a uma tentativa de resguardo da soberania do Estado em detrimento das possíveis interferências dos organismos internacionais.
} 
constrangimento internacional público, o chamado shaming. Essa é a sanção máxima da Comissão, sendo possível, ainda, fazer constar no relatório recomendações ao Estado.

No tocante à denúncia de casos individuais perante a Comissão, qualquer pessoa, grupo de pessoas ou entidade não governamental legalmente reconhecida por pelo menos um dos Estados membros da OEA pode apresentar uma denúncia. Após, inicia-se a fase da (in)admissibilidade com base nos requisitos formais, dentre os quais é possível mencionar a necessidade de esgotamento de recursos na jurisdição interna ou, alternativamente, o enquadramento em uma das exceções constantes do artigo 46.2 da Convenção Americana. "Na maioria das vezes o Estado utiliza em sua defesa como principal argumento a falta de recursos internos pelos peticionários" (Maira Beatriz GALLI; Ariel E. DULITZKY, 2000, p. 71), do que inclusive é um exemplo o caso Gonzales Lluy. De fato, "a maioria das denúncias apresentadas à Comissão Interamericana fundamenta-se em tais exceções, tendo em vista as falhas estruturais no acesso dos indivíduos aos sistemas de justiça nos países da América Latina, e a impunidade da maioria dos casos de violações de direitos humanos" (GALLI; DULITZKY, 2000, p. 74).

Recebida a denúncia, a Secretaria da Comissão a encaminha para o Estado, solicitando informações relativas aos fatos narrados, as quais devem ser prestadas no prazo de dois meses. Posteriormente, há uma espécie de réplica da parte peticionária, que faz suas observações e fornece as provas das quais dispõe. O Estado, do mesmo modo, vai manifestar-se a respeito dessas alegações. Relativamente às provas, a Convenção Americana e o Regulamento da Comissão não estabelecem um sistema rígido de valoração, a fim de que seja efetivamente averiguada a veracidade dos fatos.

Admitido o petitório, a Comissão coloca-se à disposição das partes na busca de um acordo de solução amistosa. Não havendo êxito, na fase seguinte elabora-se o relatório a que se refere o artigo 50 da $\mathrm{CADH}$, no qual constará um pronunciamento da Comissão sobre os fatos denunciados, bem como recomendações, em havendo comprovação dos fatos, para que o Estado repare os direitos violados no prazo de três meses. Se não der cumprimento às recomendações feitas no prazo, o Estado pode ser denunciado perante a Corte IDH ou a Comissão pode optar por elaborar um relatório final que fixe prazo para o cumprimento das recomendações. Se o Estado novamente não atender ao chamado, a Comissão delibera a respeito da publicação do relatório final condenando o Estado no chamado "Relatório Anual da Comissão", o qual é submetido à Assembleia Geral da OEA.

Por fim, destaca-se a possibilidade de solicitação de medidas cautelares à Comissão quando houver perigo ou risco de vida para a vítima, nos casos previstos no artigo 25 do Regulamento da Comissão (OEA, 2009a). A adoção de medidas cautelares pode ser solicitada pela Comissão relativamente a qualquer Estado membro da OEA, ainda que não tenha ratificado a Convenção Americana. Salienta-se que as medidas cautelares carecem de força convencional, eis que estabelecidas somente pelo Regimento Interno daquele órgão. Lado outro, as medidas provisórias, as quais ficam a cargo da Corte Interamericana (embora possam, também, ser solicitadas à Corte pela Comissão), não estão previstas somente no seu Regulamento, mas também na $\mathrm{CADH}$, notadamente em seu artigo 63, o que permite inferir que, caso o Estado não cumpra referidas medidas provisórias, há, de fato, uma violação à Convenção.

Noutro passo, a Corte IDH empresta um "quê" de juridicidade ao procedimento do sistema interamericano. Sua criação decorre do artigo 33 da Convenção Americana e sua sede fica em São José, na Costa Rica. Ela compõe-se de sete juízes nacionais dos Estados membros da OEA, os quais são eleitos a título pessoal dentre juristas da mais alta autoridade moral, que gozem de reconhecida competência em matéria de direitos humanos e que reúnam as outras condições necessárias ao exercício da função. Os juízes são eleitos em votação secreta para um período de seis anos, possibilitando-se a reeleição uma única vez.

A Corte exerce função consultiva e contenciosa. A primeira está amparada no fato de que qualquer membro da OEA, parte ou não da Convenção, pode solicitar parecer sobre a interpretação da Convenção ou de outros tratados relativos a direitos humanos que tenham aplicabilidade nos Estados americanos. ${ }^{3}$

O procedimento contencioso, por sua vez, inicia-se após transcorrido o prazo do Estado para cumprir as recomendações contidas no relatório previsto no artigo 50 da CADH. É necessário

\footnotetext{
${ }^{3}$ Muitas vezes as sentenças da Corte têm maior repercussão se comparadas àquela emprestada aos pareceres que ela elabora a título de opiniões consultivas. Entretanto, sua função é absolutamente fundamental. Cite-se, a título de exemplo, a OC $n^{\circ} 5 / 1985$, em que a Corte Interamericana se manifestou contrária à obrigatoriedade do diploma universitário e da inscrição em ordem profissional para o exercício da profissão de jornalista, em vista da necessidade de uma defesa ampla dos direitos da liberdade de expressão, opinião esta que repercutiu no cenário brasileiro. Outrossim, na recente $O C n^{\circ} 24 / 17$, solicitada pela Costa Rica, a Corte abonou a obrigação do Estado de reconhecer e facilitar a mudança de nome das pessoas, de acordo com a identidade de gênero de cada uma (inclusive no que se refere a menores de 18 anos). Vale lembrar que, por força da OC $n^{\circ} 15 / 1997$, a Corte entendeu que o Estado que solicita uma opinião consultiva não é o único interessado nela, de modo que a compreensão que lhe empresta a Corte mostra-se relevante a todos os Estados membros da OEA, que podem (e devem) se valer do parecer emanado.
} 
que tenha havido, por parte do Estado, aceitação da jurisdição da Corte para que a Comissão possa encaminhar a demanda. Caso contrário, o procedimento continua perante a Comissão, o que é motivo de crítica, já que supostamente enfraquece o sistema.

Quando do recebimento do caso, a Corte verifica se possui competência pessoal, material e temporal. Nesse ínterim, merece destaque o fato de que a Comissão "é o único canal de acesso para os indivíduos ao sistema interamericano, em situação de igualdade processual com os Estados-membros" (GALLI; DULITZKY, 2000, p. 64). Antonio Augusto Cançado Trindade (2002), nesse sentido, é um dos maiores críticos no que diz respeito à restrição do direito de ação internacional da vítima. Para o atual juiz da Corte Internacional de Justiça, a persistente negativa da capacidade processual do indivíduo na condição de peticionário perante a Corte é proveniente de outra época histórica, motivo pelo qual é necessária uma reforma do sistema nesse aspecto. No tocante à competência material, a Corte pode examinar qualquer caso que verse sobre a interpretação ou aplicação dos dispositivos da Convenção Americana ou outros tratados específicos. Por fim, no que se refere à competência temporal, a Corte somente conhece os casos que tenham ocorrido após a aceitação da jurisdição da Corte pelo Estado denunciado.

A Corte também deve verificar se estão presentes os requisitos formais para apresentação do caso, os quais constam do artigo 26 do seu Regulamento (2009). Iniciado o procedimento, a Comissão é chamada a participar como parte em todos os casos relativos ao exercício da Corte, cumprindo papel semelhante ao desenvolvido pelo Ministério Público no Direito doméstico. A demanda deve ser apresentada por escrito, em dez exemplares, indicando objeto, descrição dos fatos, provas, fundamentos de direito, indicação dos delegados e conclusões. Em sua defesa, o Estado pode apresentar exceções preliminares na condição de incidentes dentro do procedimento. O Regulamento da Corte prevê, em seu artigo 34 (OEA, 2009b), a fase escrita do procedimento. A fase oral consta dos artigos 45 (CORTE IDH, 2009) e seguintes do mesmo diploma. No que se refere aos meios probatórios, a Corte possui um amplo entendimento quanto ao tipo de evidência admissível.

Vale mencionar que em todos os casos de extrema gravidade e urgência, a exemplo do que já ocorre na Comissão, com as medidas cautelares, a Corte pode estabelecer medidas provisórias para evitar danos irreparáveis, as quais, é bom reiterar, têm força convencional e, portanto, vinculam os Estados partes.

Por fim, a sentença proferida pela Corte é definitiva e inapelável e dela vai constar a eventual responsabilidade do Estado demandado pelos fatos apresentados e as respectivas reparações ou indenizações devidas.

Por fim, é importante lembrar a advertência que há muito faz Cançado Trindade (2002), no sentido de que os Estados geralmente não causam embaraço às reparações de caráter pecuniário, não ocorrendo o mesmo, infelizmente, com as demais modalidades de sanção, especialmente no que diz respeito às determinações que flexibilizam, na essência, o conceito de soberania, eis que determinam reformas estruturais e institucionais dentro dos próprios Estados. Isso evidencia, de certa maneira, o motivo pelo qual os chamados DESC (direitos econômicos, sociais e culturais) são tão fundamentais em cenários de profundas desigualdades sociais. Eles não se consolidam sem as reformas estruturais, institucionais e até mesmo simbólicas que não raro são determinadas pela Corte. Sobre essas tensões falaremos nos itens seguintes, a partir da análise do Caso Gonzales Lluy.

\section{O caso Gonzales Lluy vs. Equador: as potencialidades (e limitações) de um julgado}

Talía Gabriela Gonzales Lluy nasceu em 08 de janeiro de 1995, em Cuenca, capital da província de Azuay, no Equador. Em 20 de junho de 1998, então com três anos de idade, Talía teve uma severa hemorragia nasal, tendo sido levada por sua mãe, Teresa, ao Hospital Universitário Católico, onde ficou internada por dois dias. Posteriormente, Teresa levou Talía à Clínica Humanitária Fundação Pablo Jaramillo, na qual foi diagnosticada com um grave quadro de púrpura trombocitopênica idiopática, doença autoimune caracterizada por níveis baixos de plaquetas, células sanguíneas que previnem o sangramento. Em virtude disso, o médico responsável determinou com urgência que fosse providenciada uma transfusão sanguínea para a menina, diante do que Teresa recorreu ao banco de sangue da Cruz Vermelha de Azuay, em atividade desde 1951. No local, foi informada de que deveria angariar doadores, tendo contatado alguns conhecidos, dentre os quais o Sr. HSA. ${ }^{4}$ Salientamos que os instrumentos normativos local e nacional estabeleciam a obrigatoriedade de realização de exames de qualidade do sangue previamente à transfusão, como é habitual nesse tipo de procedimento.

\footnotetext{
${ }^{4} \mathrm{O}$ nome de alguns dos envolvidos no caso não foi divulgado. No entanto, é importante mencionar que, embora a Comissão Interamericana tenha tomado o cuidado de submeter a demanda à Corte com o título "TGGL y familia vs. Ecuador", quando da apresentação do escrito de solicitações e argumentos, os representantes informaram que Talía, na ocasião já maior de idade, decidiu não preservar sua identidade em sigilo. De igual maneira, sua mãe tornou público que se chamava Teresa. Diante dessa decisão das vítimas, a Comissão passou a denominar o caso como "Gonzales Lluy y otros Vs. Ecuador".
} 
Em 22 de junho de 1998, enfim, Talía recebeu a primeira transfusão sanguínea na Clínica Humanitária. Somente em 23 de junho de 1998, ou seja, após efetivado o procedimento, a Sra. $E O Q$, bioquímica do banco de sangue da Cruz Vermelha, efetuou os exames da amostra de sangue do Sr. HSA, incluindo o de HIV. Em 29 de junho de 1998, Talía recebeu alta. O banco de sangue contatou o Sr. HSA para repetir o exame, embora não tenha dito nada a respeito da possibilidade de contaminação por HIV num primeiro momento. Nos dias 28 de julho e 13 de agosto de 1998 e em 15 de janeiro de 1999, realizaram-se novos exames sanguíneos que confirmaram, enfim, que Talía era uma pessoa e, mais especificamente, uma criança com HIV.

Diante desse quadro, Teresa tentou socorrer-se judicialmente com uma ação penal, ajuizada em 29 de setembro de 1998. O Segundo Tribunal Penal de Azuay reconheceu que Talía recebeu transfusão com sangue contaminado. No entanto, em 28 de fevereiro de 2005, a Corte Superior de Justiça de Azuay declarou a prescrição da pretensão de Talía.

Para além da ação penal, Teresa ajuizou ação civil de reparação de danos, aludindo ao fato de que é pessoa pobre, a fim de se isentar das custas do processo, o que lhe foi outorgado. Em 18 de maio de 2006, a Corte Superior de Justiça de Cuenca declarou a nulidade do feito, devolvendo o expediente ao foro de origem, sob o argumento de que não se pode demandar a indenização civil derivada de infração penal enquanto não exista uma sentença penal condenatória. Consequentemente, à vista da ausência de sentença penal transitada em julgado relativamente à infração, a Corte entendeu que não se cumpriu requisito indispensável para admitir a ação civil, o que fulminou de nulidade toda a demanda.

Nada obstante as violações acima narradas, Talía sofreu duro golpe em um dos direitos sociais mais elementares a que tem (ou deveria ter) direito o ser humano: a educação. Em setembro de 1999, então com cinco anos de idade, Talía foi inscrita na Escola de Educação Básica "Zoila Aurora Palacios", onde assistiu às classes normalmente por dois meses. No entanto, a professora APA, ao descobrir que Talía era portadora do vírus HIV, comunicou a direção superior a respeito e, em 03 de fevereiro de 2000, o veredicto final da diretora da instituição de ensino foi no sentido de não mais receber Talía, mesma oportunidade em que lhe entregou os papéis de desligamento. Mais uma vez, Teresa recorreu, com a ajuda do Comissário da Defensoria do Povo de Azuay, a um tribunal administrativo, sem, no entanto, lograr êxito. Após a audiência pública, o Subsecretário Regional de Educação entendeu que "Ias leyes educativas da[ba]n facultad a los directivos de los establecimientos [para] que cuando exist[iera] inminente riesgo en contra de los educandos pu[dieran] tomar medidas en salvaguarda del resto de educando" (CORTE IDH, 2015, p. 36). O tribunal considerou, ainda, que as autoridades educativas procederam nos termos da lei, considerando a enfermidade de Talía, a qual implicava um risco de contaminação aos demais estudantes, sendo que "frente a [ese] conflicto [era] obvio señalar que prevalece el derecho de la mayoría con respecto a un caso particular" (CORTE IDH, 2015, p. 38).

Por fim, ainda no que diz respeito aos fatos, a família Lluy sempre teve escassos recursos, mas com o contágio de Talía foram obrigados a se mudar em múltiplas ocasiões em razão da exclusão social a que foram entregues: uma cruel discriminação, nas palavras de Teresa, que não recebeu amparo do Estado e muito menos possibilidades de trabalho digno para sustentar-se e à sua família.

A petição foi recebida pela Comissão em 26 de junho de 2006, tendo sido submetida à Corte em 18 de março de 2014. Preliminarmente, o Estado alegou incompetência parcial da Corte relativamente a fatos estranhos ao marco fático e violações a direitos fora dos estabelecidos pela Comissão em seus informes, bem como a falta de esgotamento de recursos internos. No tocante à primeira alegação, a Corte entendeu que se trata de questão de mérito. ${ }^{5}$ Quanto ao esgotamento de recursos internos, os juízes afirmaram que, no caso concreto, as ações disponibilizadas às vítimas não se mostraram efetivas e nem adequadas para a determinação da responsabilidade dos fatos, de modo que afastaram a exceção preliminar, relativizando o requisito de esgotamento dos recursos internos.

No mérito, duas questões muito específicas demarcam a importância deste caso para a temática dos direitos humanos. A primeira delas diz respeito ao fato de que foi a primeira vez em que a Corte reconheceu o direito à educação com base no Protocolo Adicional à Convenção Americana sobre Direitos Humanos em Matéria de Direitos Econômicos, Sociais e Culturais ("Protocolo de San Salvador") (OEA, 1988). ${ }^{\circ}$

\footnotetext{
${ }^{5}$ As questões de mérito são aquelas que tocam o que os juristas chamam de "fundo do direito" em discussão, já que transcendem a pauta da (in)admissibilidade da demanda, materializada, por exemplo, em petições que não preencham os requisitos formais, que não exponham fatos que caracterizem possíveis violações de direitos, que sejam manifestamente infundadas ou cuja improcedência dos pedidos seja evidente ou, também, se for reprodução de outra petição ou comunicação. As hipóteses que obstaculizam a análise do mérito constam do art. 47 da CADH.

${ }^{6}$ A Corte IDH pronunciou-se pela primeira vez em relação ao artigo 26 do Pacto de São José, o qual alicerça o Protocolo Adicional, no caso Lagos del Campo vs. Perú, em 2017. A temática dos DESC, portanto, é recente no órgão jurisdicional do sistema interamericano.
} 
A segunda questão, igualmente fundamental, cinge-se ao que consta das razões de decidir do julgamento. A Corte reconheceu expressamente, ao longo da fundamentação do caso, que a situação de vulnerabilidade a que Talía foi exposta está imiscuída na chamada discriminação interseccional, categoria não tão recente na seara dos movimentos sociais, mas cujo ineditismo na cena jurídica não se pode negar. Sobre essas duas importantes especificidades do caso Gonzales Lluy, discorremos a seguir.

\subsection{A importância do Protocolo de San Salvador para os direitos humanos nas Américas}

Um "olhar a voo de pássaro" sobre os casos em tramitação e já julgados no SIDH permite evidenciar que, ao contrário do que ocorreu no Tribunal Europeu de Direitos Humanos, aqui, muitas vezes, a visibilização e a proteção das vulnerabilidades têm sido desenvolvidas a partir dos direitos econômicos, sociais e culturais e, portanto, sob a perspectiva da redistribuição (também e especialmente). Roger Raupp Rios (2007) bem assevera que, no SIDH, a proteção das minorias sexuais, ${ }^{7}$ por exemplo, tem evoluído majoritariamente a partir dos casos nos quais a discriminação por orientação sexual implicou negativa de determinado direito de cunho social ou econômico, como o tratamento de saúde e benefícios da seguridade social. Com efeito, no contexto latinoamericano, a temática da identidade surge de forma oblíqua, quase torta, muitas vezes indiretamente, atravessada em meio a outras discussões também relevantes, mas que fazem com que o cerne da questão (nesse caso, a discriminação) seja enuviado.

De fato, a América Latina infelizmente segue tendo como denominador comum entre seus países uma desigualdade social abismal. No-entanto, como bem assevera Luiz Jorge Mendonça (2009, p. 78), "se a pobreza na América Latina é explicada pelo tipo de inserção internacional determinado pelo capital, a desigualdade é ampliada principalmente por razões internas ao corpo social". Isso elucida o motivo pelo qual os direitos econômicos, sociais e culturais são, em sua essência, tão fundamentais e ao mesmo tempo tão vilipendiados no cenário latino-americano.

Nesse contexto de fracas democracias, exclusão, centralismo do poder político, desigualdade social, impunidade, violência e (auto)percepção de colonialidade, não surpreende que parcela considerável das represálias verificadas no continente deságue justamente nos chamados DESC. Como bem assevera Isaiah Berlin (2002),

oferecer direitos políticos ou salvaguardas contra a intervenção do Estado a homens seminus, analfabetos, subnutridos e doentes é zombar de sua condição: eles precisam de ajuda médica ou educação antes de poderem compreender ou aproveitar um aumento em sua liberdade (p. 231).

É que no lugar de salvaguardas em face da intervenção do Estado, estamos visualizando, ainda que abstratamente falando, identidades e vulnerabilidades que não podem "salvar-se puxando os próprios cabelos", a exemplo de um certo Barão de Münchhausen. ${ }^{8}$ São, antes, sujeitos que demandam uma proteção efetiva do Estado, que respeite sua autonomia e possibilidades de eleição em torno do que seja uma vida boa. Mas para poder escolher o que é uma vida boa e, mais, para viver a partir de uma subjetividade autônoma, é preciso garantir um mínimo existencial. ${ }^{9}$

Nesse sentido, no que se refere às tensões existentes entre os DESC e os direitos civis e políticos na seara global, algumas considerações são fundamentais. Para atribuir juridicidade à Declaração Universal de Direitos Humanos, iniciou-se em 1949 um processo, cuja conclusão se deu apenas em 1966, visando à elaboração de dois tratados: o Pacto Internacional sobre Direitos Civis e Políticos (PIDCP) e o Pacto Internacional dos Direitos Econômicos, Sociais e Culturais (PIDESC), referências imprescindíveis para o exame do regime normativo de proteção dos direitos humanos

\footnotetext{
${ }^{7}$ O caso Gonzales Lluy, inclusive, poderia ser enquadrado como uma demanda em cujo cerne está o direito à saúde de minorias sexuais. Em que pese o contágio de Talía tenha se dado mediante transfusão sanguínea, é sabido que a discriminação sofrida pelas pessoas soropositivas guarda uma relação muito íntima com o sexo e tudo o mais que o tangencia. Muito embora as formas de contágio sejam, é evidente, diversas, circula no imaginário social uma infundada associação imediata no sentido de que portar o vírus significa, de alguma maneira, uma transgressão e, ao fim e ao cabo, uma promiscuidade, o que obviamente simplifica (e diminui) em demasia a complexa realidade de um soropositivo e do seu passado.

${ }^{8}$ Karl Friedrich Hieronymus von Münchhausen (1720-1797) foi um militar e senhor rural alemão. Suas histórias um tanto quanto exageradas alicerçaram a série "As aventuras do Barão de Münchhausen". Uma das suas mais famosas peripécias foi a fuga do pântano do qual afundara junto de seu cavalo, o que só conseguiu fazer puxando os próprios cabelos.

9 Juridicamente falando, o mínimo existencial traduz um ponto de partida, justamente por incluir a satisfação de condições materiais básicas para uma vida digna, tais como saúde, alimentação e habitação. Grosso modo, implica libertar o sujeito da angústia da existência. A categoria tem sido utilizada pelos tribunais brasileiros em reiteradas decisões cujo escopo é a promoção de condições mínimas para uma vida humana, a exemplo da Ação de Descumprimento de Preceito Fundamental (ADPF) $n^{\circ} 45$, em que o Supremo Tribunal Federal defendeu uma posição mais ativa do Poder Judiciário na implementação das políticas públicas (e notadamente no controle jurisdicional das políticas econômicas), tudo isso para garantir a efetividade dos direitos de segunda geração (os chamados DESC), os quais exigem um facere do Estado.
} 
(RAMOS, 2012). Ambos os Pactos foram aprovados pela Assembleia Geral da ONU em 1966, mas somente entraram em vigor em 1976. É importante esclarecer as razões pelas quais foram elaborados dois pactos, e não somente um documento geral que abrangesse todas as categorias (direitos civis, políticos, econômicos, sociais e culturais), como ocorreu no âmbito da União Africana, com sua Carta Africana dos Direitos Humanos e dos Povos. De fato, quando se iniciaram as tratativas, a proposta era de elaboração de um único pacto. Contudo, por sugestão das nações ocidentais, em 1951 a Assembleia Geral (OEA, 1951) determinou que fossem redigidos dois documentos distintos. A principal alegação da qual se valeram os países ocidentais foi a de que os direitos políticos e civis se aplicavam automaticamente, ao passo em que os direitos sociais, econômicos e culturais demandam reformas estruturais, realizando-se progressivamente. Os países socialistas argumentaram que nem todas as nações tinham condições de proporcionar direitos civis e políticos de forma automática. Não surpreende, porém, que tenha prevalecido a posição ocidental (José Augusto Lindgren ALVES, 1994).

Essa trajetória histórica do sistema global de proteção de direitos humanos é muito similar àquela verificada no âmbito da OEA. É que quando da promulgação da Convenção Americana de Direitos Humanos, em 1969, a menção aos direitos sociais, econômicos e culturais ficou restrita ao Capítulo III, em cujo bojo se lê que os Estados Partes comprometem-se a adotar providências interna e externamente a fim de conseguir progressivamente a plena efetividade de direitos que decorram de normas econômicas, sociais e culturais, na medida dos recursos disponíveis (OEA, 1969).

O Protocolo de San Salvador foi adotado pela Assembleia Geral da OEA em 17 de novembro de 1988. Em uma região marcada por desigualdades sociais e pelo contraste entre a riqueza ostensiva de poucos e a miséria de milhões, o instrumento normativo veio ao encontro da necessidade de aferir o cumprimento dos direitos sociais em sentido amplo pelo Estado.

Em seu preâmbulo enaltece a relação indissociável que se estabelece entre os direitos econômicos, sociais, culturais, civis e políticos, reiterando que os direitos humanos constituem um todo indissolúvel que protege a dignidade humana. A enunciações dessa ordem soma-se um linguajar tímido que possibilita que o Estado implemente direitos sociais de maneira lenta e progressiva, levando em consideração os seus recursos disponíveis e o seu grau de desenvolvimento (RAMOS, 2017).

De fato, o Protocolo intenta proteger o direito ao trabalho, à previdência social, à saúde, ao ambiente sadio, à alimentação, à educação, à cultura e à proteção da família. Para além disso, consigna expressamente o direito de crianças e idosos, bem como das pessoas com deficiências, canonizando a proteção de grupos em cujo bojo circulam atravessamentos que tocam o reconhecimento e a redistribuição financeira, conceitos extensamente analisados por Nancy Fraser (2007). A autora propõe uma concepção bidimensional de justiça que combine reconhecimento e redistribuição (e, mais recentemente, representação). Em seu entendimento, a justiça requer arranjos sociais que permitam a todos os indivíduos interagirem entre si com paridade, por meio de uma distribuição de recursos materiais (redistribuição) que garanta a independência dos integrantes dessa sociedade e a institucionalização de um padrão cultural de respeito por todos (reconhecimento), para que as oportunidades sejam iguais. Fraser também discorre sobre a necessidade de reconhecimento social enquanto questão de estatuto social.

Um detalhe (e um inconveniente) importante do Protocolo diz respeito aos mecanismos de monitoramento. É que ele somente erigiu a possibilidade de petições para o caso de violações de direitos sindicais (excetuado o direito de greve) e do direito à educação. Quanto aos demais direitos sociais, o único mecanismo de responsabilização internacional à disposição consiste na apresentação, pelos Estados membros, de relatórios periódicos cuja análise fica a cargo do Conselho Interamericano de Desenvolvimento Integral (CIDI).

Essa fragilidade do Protocolo e do sistema como um todo deságua no fato já mencionado anteriormente de que os relatórios da Comissão e os julgamentos da Corte têm tutelado os DESC de maneira transversal. Isto é, há uma tendência de proteção indireta desses direitos, consagrandoos não como direitos autônomos, mas como direitos sujeitos ou conexos a outros direitos fundamentais, a exemplo principalmente do direito à vida, à integridade e à liberdade pessoal.

Com efeito, foi o que se verificou no caso em discussão: a Corte declarou o Equador internacionalmente responsável pela violação do direito à vida e à integridade pessoal, à educação e à garantia judicial de duração razoável do processo penal em prejuízo de Talía. Também reconheceu a responsabilidade do Equador pela violação do direito à integridade pessoal de Teresa e Iván Lluy, mãe e irmão de Talía. A ênfase está, portanto, claramente direcionada para os direitos individuais.

Por isso, apesar da importância do Protocolo para a consolidação de um sistema regional mais justo e efetivo, das decisões e relatórios da Corte e da Comissão, extraímos que o SIDH ainda considera os DESC como direitos cuja força não é capaz de se impor aos Estados, na medida em que somente admite a sua violação quando também violados os direitos fundamentais individuais. 
Noutro passo, reconhece-se que, talvez, essa tenha sido a alternativa encontrada pelo SIDH para viabilizar o mínimo existencial em regiões ainda marcadas por severas dificuldades econômicas e pela avassaladora diferença no tocante à distribuição de renda. Surpreende, por outro lado, que no Tribunal Europeu, em que as demandas geralmente são essencialmente identitárias (repisa-se, em regra) e, portanto, ao contrário do que ocorre no sistema interamericano (em que as demandas são potencialmente em busca de redistribuição financeira), o fio que conduz os instrumentos normativos é, também, no sentido de se tutelar direitos civis e políticos, afinados com a pauta dos direitos individuais. ${ }^{10} \mathrm{Em}$ resumo: têm-se duas realidades de abismal diferença e, por outro lado, instrumentos normativos muito parecidos em sua gênese e aplicabilidade.

Destarte, e por isso, acredita-se na potência da sentença do Caso Gonzales Lluy "guardadas as devidas proporções". É necessário visibilizar a importância dos direitos sociais, econômicos e culturais de maneira explícita nos relatórios e decisões do SIDH. Isto é, justamente levando em consideração o fato de que a América Latina é uma região vulnerável (ou melhor, que foi vulnerabilizada) no cenário internacional. Talvez seja eficaz, pelo menos do ponto de vista simbólico, repercutir os DESC como uma categoria autônoma merecedora da mesma proteção de que já gozam os direitos civis e políticos, não esquecendo, é evidente, o caráter de interdependência que se aninha entre todas essas categorias.

A sentença do Caso Gonzales Lluy, entretanto, traz uma grata surpresa ao longo de sua fundamentação no tocante à discriminação interseccional. Com uma sensibilidade acurada, os julgadores conseguem captar a particularidade de Talía, o que pode se constituir em um importante precedente relativamente aos sistemas regionais de proteção de direitos humanos no tocante à consolidação progressiva dos DESC.

\subsection{Discriminação interseccional e a identidade como simulacro}

A ideia de justiça parte de e deságua sempre numa tensão fundamental entre o Direito como ciência e, portanto, como uma categoria de aplicabilidade universal, que se destina a todos e todas numa perspectiva abstrata - e a análise do caso concreto, com suas inúmeras particularidades que o singularizam diante de situações muitas vezes semelhantes (mas são somente isso: situações semelhantes, e não iguais). Essa dialogicidade, quase inconciliável, mas sobre a qual os juristas se debruçam (ou pelo menos deveriam fazê-lo) em busca da justiça do caso concreto, não pode aceitar premissas pré-estabelecidas e pré-concebidas, sob pena de "julgarem um livro pela capa". O Direito Penal e seus protagonistas estão bem "acostumados" com essa característica quase que perversa do Direito de estabelecer identidades de maneira sedentária, isto é, a partir da noção de previsibilidade. De fato,

houve, na razão jurídica, uma vontade de simplificação da complexidade do mundo da vida. Privados de Deus, os juristas modernos buscaram, incessante e inconscientemente, um novo lugar de construção institucional de uma sensação existencial de confiança. Mesmo diante de uma manifesta multiplicidade e desordem dos fenômenos, buscaram a simplicidade através de aforismos que adquiriram o status de princípios de uma nova ordem (André Leonardo Copetti SANTOS; Doglas Cesar LUCAS, 2015, p. 125).

Essas considerações preliminares são fundamentais para compreender a discriminação, conceito central no caso Gonzales Lluy. A discriminação direta propõe certas normas ou ações tendentes a estigmatizar o diferente ou simplesmente excluí-lo. Falamos, aqui, das regras e códigos instituídos para salvaguardar espaços de poder, ou seja, a exclusão explícita de um grupo social em razão de seu sexo, raça, religião, idade, posicionamento político etc. que deságua na manutenção dos membros de um determinado grupo em situação desvantajosa ou desfavorável e, noutro passo, na manutenção de outro grupo em situação confortável.

Sabemos, no entanto, que a discriminação hoje encontra, em face do legado moderno de igualdade de todos perante a lei (por mais abstrata que seja essa igualdade), certos entraves a realizar-se do modo direto, manifesto, explícito. Com isso, como bem asseverou Michel Foucault (1999), estabelecem-se novas formas de discriminação e exclusão. Apesar da diminuição significativa de instrumentos normativos de cunho discriminatório e do incremento de práticas das instituições no sentido de primar pela igualdade, existe, de todo modo, uma grande margem para o desenvolvimento de condutas sutis, cuja natureza é mais difícil de perceber.

Nesse contexto, a discriminação indireta consiste na imposição de normas e regras (não somente do ponto de vista formal, enquanto norma jurídica, mas também na perspectiva de norma social, de padrão de conduta e comportamento) que em primeira instância parecem inofensivas, mas que na prática não são, e não obstante, trazem consequências nefastas.

\footnotetext{
${ }^{10} \mathrm{Em}$ que pese o SIDH tenha consagrado os DESC no Protocolo de San Salvador, o Tribunal Europeu não detém instrumentos formais de defesa dessa categoria de direitos. Por isso, esta Corte tem proporcionado os direitos que exigem prestações positivas do Estado a partir do princípio da proporcionalidade na interpretação dos direitos de primeira geração (vida, liberdade etc.), ou seja, também de forma indireta.
} 
Para além dessas modalidades de discriminação, grupos minoritários vivenciam ainda a autodiscriminação, isto é, uma percepção inferiorizada de si. Trazem na psique e na alma a constante lembrança de que poderiam e deveriam ser diferentes, e nisso se materializa uma vigilância internalizada que oprime e castra as inúmeras possibilidades que a diversidade humana oferece. Constituem-se, assim, mecanismos internos de repressão, tão dolorosos quando aqueles mecanismos alheios ao próprio sujeito.

Especificamente no tocante ao caso Talía, a Corte reconheceu expressamente que convergiram, de modo interseccional, múltiplos fatores de vulnerabilidade e risco de discriminação associados à sua condição de criança, mulher, pessoa em situação de pobreza e pessoa com HIV.

Nesse cenário específico de vulnerabilidade econômica, são esclarecedoras as elucidações de Kimberlé Williams Crenshaw (2002), na medida em que

a discriminação interseccional é particularmente difícil de ser identificada em contextos onde forças econômicas, culturais e sociais silenciosamente moldam o pano de fundo, de forma a colocar as mulheres em uma posição onde acabam sendo afetadas por outros sistemas de subordinação. Por ser tão comum, a ponto de parecer um fato da vida, natural ou pelo menos imutável, esse pano de fundo (estrutural) é, muitas vezes, invisível (p. 176).

Com efeito, a discriminação a que foi exposta a vítima não é exatamente uma soma de múltiplos fatores, mas uma forma específica de discriminação que resultou da intersecção desses fatores. Dito de outro modo, se Talía fosse negra, muito possivelmente haveria outro traço de identificação que Ihe agregaria ainda mais vulnerabilidade. Daí por que Crenshaw (2012, p. 09) aduz que "tanto as questões de gênero como as raciais têm lidado com a diferença. O desafio é incorporar a questão de gênero à prática dos direitos humanos e a questão racial ao gênero". Por certo, se Talía fosse, além de negra, transexual, outras consequências, provavelmente (e, é bom lembrar, provavelmente porque é sempre uma suposição) mais severas, daí decorreriam. Então,

la discriminación que vivió Talía no sólo fue ocasionada por múltiples factores, sino que derivó en una forma específica de discriminación que resultó de la intersección de dichos factores, es decir, si alguno de dichos factores no hubiese existido, la discriminación habría tenido una naturaleza diferente. [...] En suma, el caso de Talía ilustra que la estigmatización relacionada con el VIH no impacta en forma homogénea a todas las personas y que resultan más graves los impactos en los grupos que de por sí son marginados (CORTE IDH, 2015, p. 87-88).

Essas observações da Corte são fundamentais porque conseguem captar a particularidade de cada sujeito. É essa particularidade, inclusive, que faz Crenshaw (2012) afirmar que "uma das razões pelas quais a interseccionalidade constitui um desafio é que, francamente, ela aborda diferenças dentro da diferença" (p. 09).

Com efeito, diante do quadro de total desrespeito ocorrido em relação à Talía e à sua família e da dificuldade de subsumir o caso a instrumentos normativos específicos (até mesmo porque estamos a tratar da diferença na diferença, o que revela fragilidades também e especialmente no tocante ao enquadramento jurídico-legal), a Corte adotou uma interessante estratégia: equiparou a vítima - portadora do vírus HIV - à pessoa com deficiência, nos termos da Convenção das Nações Unidas sobre os Direitos da Pessoa com Deficiência (BRASIL, 2008). Vale a pena transcrever trecho esclarecedor da sentença:

Como parte de la evolución del concepto de discapacidad, el modelo social de discapacidad entiende la discapacidad como el resultado de la interacción entre las características funcionales de una persona y las barreras en su entorno. Esta Corte ha establecido que la discapacidad no se define exclusivamente por la presencia de una deficiencia física, mental, intelectual o sensorial, sino que se interrelaciona con las barreras o limitaciones que socialmente existen para que las personas puedan ejercer sus derechos de manera efectiva. En este sentido, el convivir con el VIH no es per se una situación de discapacidad. Sin embargo, en algunas circunstancias, las barreras actitudinales que enfrente una persona por convivir con el VIH generan que las circunstancias de su entorno le coloquen en una situación de discapacidad (CORTE IDH, 2015, p. 69).

Nessa perspectiva, a Corte afirma que, em que pese portar o HIV não seja exatamente uma discapacidade, essa condição é potencialmente excludente a depender de barreiras atitudinais e sociais. Por isso, a determinação sobre se alguém pode ser considerado uma pessoa com deficiência depende mais do seu entorno (e, portanto, do outro) do que exatamente de um diagnóstico. Quer dizer, a pessoa que vive com o vírus, ou mesmo a mera suposição de que ela o tem, pode criar barreiras sociais e comportamentais para que ela exerça os seus direitos em condições de igualdade com os demais.

De tudo isso, não se pode concluir outra coisa a não ser que a interseccionalidade escancara o fato de que cada indivíduo é, está e sempre estará no mundo na condição de unicum a que faz menção Friedrich Nietzsche (1999). Sua morte significa fulminar uma existência e dar lugar a inúmeras outras, que são existências outras, e que justamente por serem outras, podem até guardar semelhança com as demais, mas são únicas, singulares. Aquele unicum jamais retorna. 
Isso implica que as opressões vivenciadas por esse sujeito, em que pese possam "conversar" numa perspectiva mais abrangente e mesmo de grupo, de coletividade, são muito particulares e igualmente únicas. Não se trata, portanto, de uma discriminação múltipla, mas de uma discriminação interseccional e, ao mesmo tempo, única, pelo fato óbvio (mas muitas vezes esquecido) de que o conceito de identidade, levado ao extremo, conduz a uma tensão inconciliável com o todo.

A identidade absoluta, portanto, é simplesmente falaciosa (talvez seja utópica, se for um desejo). Dito de outro modo, a identidade é sempre precária e provisória. O simulacro, nesse sentido, é sempre construído sobre uma disparidade, sobre uma diferença. A razão pode estar a serviço da força moral e, nesse ínterim, ela assume a posição de juíza máxima de valores. É exatamente como juíza de valores que a razão condena tudo aquilo que lhe pareça um tanto ou quanto descentrado, desregrado, tudo aquilo que não se enquadra em um modelo "prefixado". É também por essa razão que a diferença lhe escapa completamente à compreensão (Regina SCHÖPKE, 2012).

Por conseguinte, a diferença ameaça a razão e seus equilíbrios estáveis, estáticos, sedentários, os quais operam a partir da identidade e da semelhança. É por isso que no Filebo de Platão (2012) parece ser fundamental impedir o vir à luz do caótico, o que significa barrar justamente a diferença. Ou seja, o simulacro, o caos, a ausência do modelo devem ser sempre combatidos.

De fato, a diferença pura é o simulacro que emerge e destrói o sonho da identidade plena. Gilles Deleuze (1988), nesse sentido, inova por tentar introduzir uma ideia que possa abranger todas as sinuosidades e aparições da diferença, sem, contudo, reduzi-la à negação, coisa que a representação faz. Tomar a diferença desta forma, como atributo ou negação, é diminuir-lhe o valor, reduzi-la ao desimportante. A diferença é, em verdade, um acontecimento do próprio ser. É por isso que em Deleuze "não há mais mundo sensível e mundo inteligível, mas um único mundo, um mundo de corpos e de intensidades, de corpos e de acontecimentos, de seres concretos e virtualidades" (SCHÖPKE, 2012, p. 194). Ou seja, é preciso compreender cada coisa como uma coisa ou obra autônoma, sendo a identidade e a semelhança meras simulações no jogo da existência, do ser e do devir (DELEUZE, 1988).

Trazendo essa breve reflexão filosófica em torno da diferença para o Caso Gonzales Lluy, parece-nos fundamental apontar a potência da sentença da Corte justamente no sentido de reconhecer essas tensões que são inerentes à identidade e à singularidade do ser humano.

A pequena Talía, criança, menina, de escassos recursos, proveniente de uma região pobre, não é igual à outra Talía, igualmente criança, igualmente menina etc. São duas pessoas, são duas situações, são duas vidas e duas formas absolutamente distintas (mas sempre demasiadamente humanas e, por isso mesmo, diferentes) de ser e estar neste mundo. Como bem apontam Lucas e Santos (2016):

As identidades não podem ser vistas como atributos ou características do inimigo. A diferença do outro não pode ser uma diferença carregada de exclusão. É saber que não existe igualdade sem diferenças, mas a diferença, como manifestação da humanidade comum, não é, por si só, causa ou motivação para nenhum tipo de arbítrio. As estratégias normativas de se reconhecer a identidade não podem acabar, rivalizar ou vulnerabilizar com as diferenças, mas devem conduzir um processo de responsabilização recíproca, capaz de atender aos reclamos do Direito enquanto mecanismo de proteção da máxima liberdade das diferenças publicamente confrontadas e ajustadas (p. 206).

Problematizar a identidade e a diferença, nesses termos, parece um passo fundamental rumo à concretização de direitos humanos que se propõem universais, mas não castradores das possibilidades que a vida e os corpos oferecem.

\section{Considerações finais}

Neste breve texto intentamos demonstrar que, ao fim e ao cabo, o "grande problema" das sociedades reside sempre na diferença, naquilo que está no Outro (e que, portanto, não está em $\mathrm{mim}$ ), naquilo que separa, quando em verdade deveria unir. Verificamos que aquela universalidade que deu a cor e o tom dos direitos humanos desde a Modernidade não mais responde às demandas da sociedade contemporânea, pois a tutela efetiva de direitos humanos depende de sua compreensão em contextos culturais (e existenciais) muito específicos.

Isto é, reconhecer a potência da diversidade, que por sua vez é materializada na raça, na pertença cultural, no sexo, no gênero, na orientação sexual, nas percepções políticas, nas crenças, nas discapacidades físicas ou intelectuais, é fundamental para avançar em termos de direitos humanos. Outrossim, é possível (e necessário) reformular o ideal universal dos direitos humanos (não numa perspectiva castradora, mas inclusiva), o que demarca um passo fundamental, também, na concretização desses direitos.

Uma análise detida da sentença da Corte do Caso Gonzales Lluy permite engendrar duas conclusões fundamentais: a primeira delas (e aqui reside um ponto de crítica ao julgado) diz 
respeito à problemática em torno dos direitos econômicos, sociais e culturais, haja vista que a argumentação da Corte, não somente no Caso Gonzales Lluy, mas em inúmeros outros que trazem em seu seio a questão dos DESC, remete a uma narrativa relativamente confortável no sentido de não se imiscuir nas estruturas dos Estados. Isto é, a Corte parece tecer uma linha argumentativa que lhe permite interferir minimamente na estrutura soberana dos Estados, ainda que por vias um tanto quanto tortas e que, portanto, não encara diretamente a problemática daquela categoria de direitos humanos. Um enfrentamento direto da fragilidade dos Estados em oferecer o mínimo existencial aos sujeitos e das escolhas políticas em termos de distribuição de renda teria, talvez simbolicamente, sobretudo, mais força.

Por outro lado, uma segunda conclusão fundamental diz respeito ao reconhecimento da condição de Talía como uma pessoa absolutamente singular, sujeita a uma forma de discriminação igualmente singular, denominada no julgado como "interseccional". São, portanto, vulnerabilidades que se atravessam (mais do que se somam) e que, justamente por isso, se particularizam em meio a outras discriminações. Fazendo isso, a Corte inaugura o primeiro julgado em que aborda expressamente a discriminação interseccional, o que permite concebê-lo como uma importante ferramenta no combate à exclusão em suas mais diversas formas.

Não podemos negar, então, que a Corte tem trabalhado com aquilo que está ao seu alcance. Prova disso é que equiparou Talía à condição de pessoa com deficiência para entregarIhe o mínimo existencial. Em regiões absolutamente carentes e vulnerabilizadas, como é o caso da América Latina, não restam dúvidas das dificuldades que enfrentam os mecanismos internacionais no sentido de interferir de maneira mais explícita nas estruturas de cada Estado. Apesar de suas limitações - fáticas, orçamentárias e, como vimos aqui, de cunho hermenêutico -, o SIDH tem feito um trabalho importante no que se refere a uma mudança de paradigma, sinalizando para novos tempos, mais inclusivos e libertadores das diferenças.

De fato, limitar-se a tolerar a diferença não basta; é preciso também amá-la, concebendoa como um traço fundamental que dá a cor e o tom da singularidade de cada criatura humana. Porque, ao fim e ao cabo, é isso o que somos, uma "identidade tragada pela diferença, cada qual sendo só uma diferença entre as diferenças" (DELEUZE, 1988, p. 94).

\section{Referências}

ALVES, José Augusto Lindgren. Os direitos humanos como tema global. São Paulo: Perspectiva; Brasília: Fundação Alexandre Gusmão, 1994.

BELCHIOR. Apenas um Rapaz Latino-Americano. Composição: Belchior. Produção: Marco Mazzola. Álbum: Alucinação. Gravadora: Polygram. Ano: 1976.

BERLIN, Isaiah. Estudos sobre a humanidade: uma antologia de ensaios. São Paulo: Companhia das Letras, 2002.

BRASIL. Decreto Legislativo no 186, de 2008. Aprova o texto da Convenção sobre os Direitos das Pessoas com Deficiência e de seu Protocolo Facultativo, assinados em Nova lorque, em 30 de março de 2007. Disponível em http://www.planalto.gov.br/ccivil_03/Congresso/DLG/DLG-1862008.htm. Acesso em 13/11/2018.

COMISSÃO ECONÔMICA PARA A AMÉRICA LATINA E O CARIBE (CEPAL). Implementación del Programa de Acción de la Conferencia Internacional sobre la Población y el Desarrollo en América Latina y el Caribe: examen del período 2009-2013 y lecciones aprendidas, 2013. Disponível em http:// repositorio.cepal.org/bitstream/handle/1 1362/3126/S2013403_es.pdf?sequence=1 \&isAllowed=y. Acesso em 24/09/2017.

CORTE INTERAMERICANA DE DIREITOS HUMANOS (CORTE IDH). Regulamento da Corte Interamericana de Direitos Humanos, 11/2009. Disponível em http://www.corteidh.or.cr/sitios/reglamento/ nov_2009_por.pdf. Acesso em 13 abr. 2017.

CORTE INTERAMERICANA DE DIREITOS HUMANOS (CORTE IDH). Gonzales Lluy vs. Ecuador. Exceções preliminares, fundo, reparações e custas, 01/09/2015. Disponível em http://www.corteidh.or.cr/docs/ casos/articulos/seriec_298_esp.pdf. Acesso em 02/08/2018.

CRENSHAW, Kimberlé. "A intersecionalidade na discriminação de raça e gênero". In: CRENSHAW, Kimberlé. Cruzamento: raça e gênero. Brasília: EDUnifem, 2012. Disponível em http://www.acaoedu cativa.org.br/fdh/wp-content/uploads/2012/09/KimberleCrenshaw.pdf. Acesso em 21/05/2019.

CRENSHAW, Kimberlé. "Documento para o encontro de especialistas em aspectos da discriminação racial relativos ao gênero". Revista Estudos Feministas, Florianópolis, v. 10, n. 1, p. 171-188, jan. 2002. Disponível em http://www.scielo.br/scielo.php?script=sci_arttext\&pid=s0104- 
026X2002000100011\&lng=en\&nrm=iso. DOI: $10.1590 /$ S0104-026X2002000100011. Acesso em $21 / 05 / 2019$.

DELEUZE, Gilles. Diferença e repetição. Tradução de Luiz Orlandi e Roberto Machado. Rio de Janeiro: Graal, 1988.

FOUCAULT, Michel. Microfísica do poder. Tradução de Roberto Machado. 14. ed. Rio de Janeiro: Graal, 1999.

FRASER, Nancy. "Mapeando a imaginação feminista: da redistribuição ao reconhecimento e à representação". Revista Estudos Feministas, Florianópolis, v. 15, n. 2, p. 291, maio 2007. ISSN 18069584. Disponível em https://periodicos.ufsc.br/index.php/ref/article/view/S0104-026X2007000200002. Doi: https://doi.org/10.1590/S0104-026X2007000200002. Acesso em 21/05/2019.

GALLI, Maria Beatriz; DULITZKY, Ariel E. "A comissão interamericana de direitos humanos e o seu papel central no sistema interamericano de proteção dos direitos humanos". In: GOMES, Luis Flávio; PIOVESAN, Flávia (Orgs.). O sistema interamericano de proteção dos direitos humanos e o direito brasileiro. São Paulo: Revista dos Tribunais, 2000. p. 53-80.

GARCÍA, Joaquín Torres. Universalismo Constructivo. Buenos Aires: Poseidón, 1944.

LUCAS, Doglas Cesar; CENCl, Ana Righi. "A identidade latino-americana como problema e a necessidade de uma proposta intercultural". In: SANTOS, André Leonardo Copetti; LUCAS; Doglas Cesar; BRAGATO, Fernanda Frizzo (Orgs.). Pós-colonialismo, pensamento descolonial e direitos humanos na América Latina. Santo Ângelo: EDFURI, 2014. p. 85-100.

LUCAS, Doglas; SANTOS, André Leonardo Copetti. "O direito à diferença e a proteção jurídica das minorias na América Latina”. Revista Direito em Debate, n. 45, jan./jul. 2016. Disponível em https:// www.revistas.unijui.edu.br/index.php/revistadireitoemdebate/article/view/5555. Acesso em 04/1 1/ 2018.

MENDONÇA, Luiz Jorge V. Pessôa de. "América Latina: da desigualdade social à desigualdade econômica". Argumentum, Vitória, v. 1, n. 1, p. 78-91, jul./dez. 2009. Disponível em http://periodicos. ufes.br/argumentum/article/view/14/16. Acesso em 20/08/2018.

NIETZSCHE, Friedrich. Schopenhauer como educador. Tradução de Adriana M. Saura Vaz. Campinas: Faculdade de Educação/EDUNICAMP, 1999.

O'DONNELL, Guillermo. "Poliarquias e a (in)efetividade da lei na América Latina”. Tradução de Otacílio Nunes. Novos Estudos, CEBRAP, p. 37-61, 1998. Disponível em https://unpabimodal.unpa.edu.ar/ bibliografia/00-A0190/00-A0190.pdf. Acesso em 21/07/2017.

ORGANIZAÇÃO DOS ESTADOS AMERICANOS (OEA). Carta da Organização dos Estados Americanos, 13/12/1951. Disponível em http://www.dhnet.org.br/direitos/anthist/marcos/hdh_carta_oea_1948.pdf. Acesso em 15/11/2016.

ORGANIZAÇÃO DOS ESTADOS AMERICANOS (OEA). Convenção Americana de Direitos Humanos, 22/ 1 1/1969. Disponível em https://www.cidh.oas.org/basicos/portugues/c.convencao_americana.htm. Acesso em 15/1 1/2016.

ORGANIZAÇÃO DOS ESTADOS AMERICANOS (OEA). Declaração Americana dos Direitos e Deveres do Homem, 04/1948. Disponível em https://www.cidh.oas.org/basicos/portugues/b.Declaracao_America na.htm. Acesso em 16/06/2017.

ORGANIZAÇÃO DOS ESTADOS AMERICANOS (OEA). Protocolo Adicional à Convenção Americana sobre Direitos Humanos em Matéria de Direitos Econômicos, Sociais e Culturais (Protocolo de San Salvador), 17/11/1988. Disponível em https://www.cidh.oas.org/basicos/portugues/ e.Protocolo_de_San_Salvador.htm. Acesso em 16/06/2017.

ORGANIZAÇÃO DOS ESTADOS AMERICANOS (OEA). Regulamento da Comissão Interamericana de Direitos Humanos, out./nov. 2009a. Disponível em http://www.cidh.org/Basicos/Portugues/ u.Regulamento.CIDH.htm. Acesso em 23/10/2017.

ORGANIZAÇÃO DOS ESTADOS AMERICANOS (OEA). Regulamento da Corte Interamericana de Direitos Humanos, 11/2009b. Disponível em http://www.corteidh.or.cr/sitios/reglamento/nov_2009_por.pdf. Acesso em 30/04/2017. 
PIOVESAN, Flávia. Direitos humanos e justiça internacional: um estudo comparativo dos sistemas regionais europeu, interamericano e africano. São Paulo: Saraiva, 2006.

PLATÃO. Filebo. Tradução de Fernando Muniz. Rio de Janeiro: EDPUC-Rio, 2012.

RAMOS, André de Carvalho. Processo internacional de direitos humanos. 2. ed. São Paulo: Saraiva, 2012.

RAMOS, André de Carvalho. Curso de direitos humanos. 4. ed. São Paulo: Saraiva, 2017.

RIOS, Roger Raupp. Em defesa dos direitos sexuais. Porto Alegre: Livraria do Advogado, 2007.

SALAZAR, Katya; CERQUEIRA, Daniel. "Las atribuciones de la Comisión Interamericana de Derechos Humanos antes, durante y después del proceso de fortalecimiento: por un balance entre lo deseable y lo posible". In: MAIA, Camila Barreta et al. (Orgs.). Desafíos del sistema interamericano de derechos humanos: nuevos tiempos, viejos retos. Bogotá: Centro de Estudios de Derecho, 2015. p. 144-189.

SANTOS, André Leonardo Copetti; LUCAS, Doglas Cesar. A (in)diferença no direito. Porto Alegre: Livraria do Advogado, 2015.

SCHÖPKE, Regina. Por uma filosofia da diferença: Gilles Deleuze, o pensador nômade. Rio de Janeiro: Contraponto, 2012.

STRECK, Lenio Luiz. Hermenêutica jurídica e (m) crise: uma exploração hermenêutica da construção do Direito. 11. ed. rev., atual. e ampl. Porto Alegre: Livraria do Advogado, 2014.

TRINDADE, Antonio Augusto Cançado. O direito internacional em um mundo em transformação. São Paulo; Rio de Janeiro: Renovar, 2002.

ZAFFARONI, Eugenio Raúl. "La historia de los derechos humanos en América Latina". In: OLGUíN, Leticia (Org.). Educación y derechos humanos: una discusión interdisciplinaria. São José da Costa Rica: Instituto Interamericano de Derechos Humanos, 1989. p. 21-80.

Pâmela Copetti Ghisleni (pcghisleni@gmail.com) é bacharel em Direito pela Universidade Regional do Noroeste do Estado do Rio Grande do Sul - UNIJUí (2015) e mestre em Direito, com ênfase em Direitos Humanos, pelo Programa de Pós-Graduaçãa Stricto Sensu em Direito da UNIJUí (2018). Cursou o Mestrado com bolsa da Coordenação de Aperfeiçoamento de Pessoal de Nível Superior (CAPES). Atualmente, é professora do Curso de Graduação em Direito da Faculdade CNEC Santo Ângelo/RS.

Doglas Cesar Lucas (doglasl@unijui.edu.br) é doutor em Direito pela UNISINOS e pósdoutor em Direito pela Università degli Studi di Roma Tre. Professor dos Cursos de Graduação, Mestrado e Doutorado em Direito da UNIJUí e do Curso de Graduação em Direito da Faculdade CNEC Santo Ângelo. Professor Colaborador do Curso de Mestrado e Doutorado da URI Santo Ângelo. Editor-chefe da Revista Direitos Humanos e Democracia (B1).

\section{COMO CITAR ESSE ARTIGO DE ACORDO COM AS NORMAS DA REVISTA}

GHISLENI, Pâmela Copetti; LUCAS, Doglas Cesar. "Direitos humanos e vulnerabilidades atravessadas". Revista Estudos Feministas, Florianópolis, v. 28, n. 2, e60174, 2020.

\section{CONTRIBUIÇÃO DE AUTORIA}

A autora e o autor escreveram o artigo em parceria, em virtude de que os temas estão afinados com as pesquisas de uma e de outro. A autora tem focado suas pesquisas na temática dos direitos sexuais, especificamente no campo do sistema interamericano de proteção e dos demais sistemas regionais. $O$ autor, a seu turno, trabalha com temas como identidade e diferença, de modo que a abordagem do texto contempla as pesquisas encabeçadas por ambos.

\section{FINANCIAMENTO}

O presente trabalho foi realizado com apoio da Coordenação de Aperfeiçoamento de Pessoal de Nível Superior - Brasil (CAPES) - Código de Financiamento 001. 


\section{CONSENTIMENTO DE USO DE IMAGEM}

Não se aplica.

\section{APROVAÇÃo DE COMITÊ DE ÉTICA EM PESQUISA}

Não se aplica.

\section{CONFLITO DE INTERESSES}

Não se aplica.

\section{LICENÇA DE USO}

Este artigo está licenciado sob a Licença Creative Commons CC-BY International. Com essa licença você pode compartilhar, adaptar, criar para qualquer fim, desde que atribua a autoria da obra.

\section{HISTÓRICO}

Recebido em $11 / 11 / 2018$

Reapresentado em 24/05/2019

Aprovado em 03/07/2019 